\title{
Dedicated to Richard Laver
}

The various authors and editors of this volume knew Rich in many different roles: as a researcher, a teacher, a mentor, a chess player, a climbing partner and as a friend. Throughout, Rich's sly but gentle sense of humor and his decency made him the best of companions. His overwhelming modesty allowed many of us to temporarily forget his remarkable mathematical achievements and relate to him informally as a peer. We take this occasion to celebrate his historical contributions to mathematics and publicly thank him for the help he gave us.

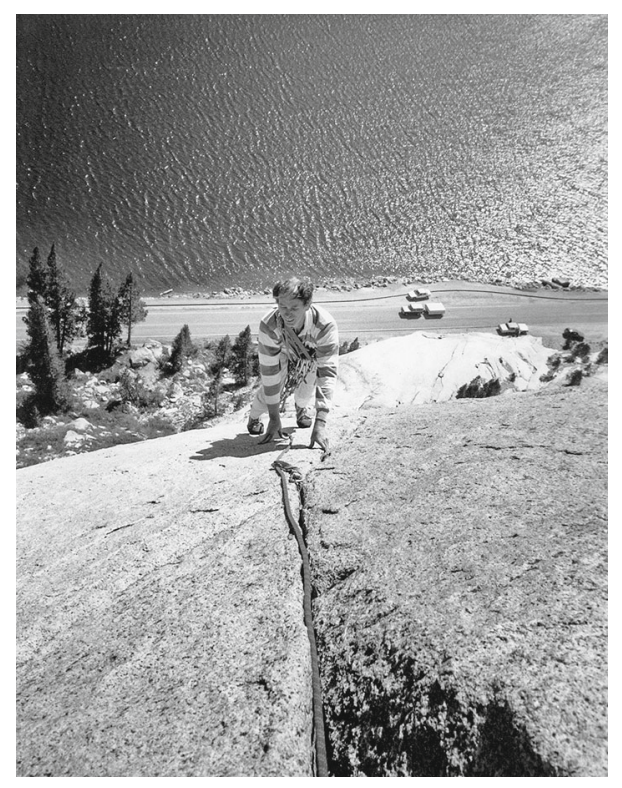

